\title{
Phosgene Toxic Effects and Influence of a New Impregnant On Protection
}

\author{
Milena Nikolić1,*, Mladen Nikolić², Dragan Nikolić , Sretko Ilić ${ }^{2}$ \\ ${ }^{1}$ Medical faculty, University of Professional Studies in Kragujevac \\ ${ }^{2}$ Chemical Technology College of Professional Studies in Krusevac
}

\begin{abstract}
Phosgene is a gas which affects the respiratory organs, causes pulmonary edema and suffocation. For the protection, activated carbon based filters are used. The filters are universal and used for a big number of pollutants. The objective of this study was to determine a new impregnant which would provide the respiratory protective filter with a greater adsorption capacity and longer service life. The activated carbon impregnation was performed with sodium and the filters were tested on a dynamic-sorption apparatus.

The study results show that the optimal amount of sodium over activated carbon is $1.3 \mathrm{mal} / \mathrm{dm}^{3}$ and this amount of sodium provides the filter with the sorption capacity of $16.96 \mathrm{~g}$ and service life of $1532 \mathrm{~s}$. Adsorbed water also has an effect on both the sorption capacity and service life of the filter. The study shows that the optimal amount of the adsorbed water in the filter activated carbon is $23 \%$ and it increases the filter sorption capacity by $18.49 \%$ and the service life up to 1674 s.
\end{abstract}

\section{Keywords: impregnant, phosgene, toxic effect, activated carbon, sodium}

\section{INTRODUCTION}

Phosgene $(\mathrm{COCl} 2)$ is a colorless gas, with rotting fruit odor. Its boiling point is $8.2^{\circ} \mathrm{C}$. Phosgene is slightly soluble in water. Higher concentrations of asphyxiators that arrives into respiratory organs causs triple effect on living organism like as:

- neurotoxic effect

- local irritant and cytotoxic

- toxic effect

In all the countries with developed chemical industry, phosgene production has been increasing. Phosgene generally exerts suffocation effects as a result of pulmonary edema. At present filters filled with activated carbon impregnated with copper carbonate, ammonium bichromate and silver nitrate are used for the protection. These filters are also used for protection from other gases and vapors. The sorption capacity of the filters impregnated in this way is $12 \mathrm{~g}$.

For the filter impregnation and filling, coconut shell based activated carbon is used. Activated carbon is among materials which have highly developed porosity. Dubinin proposed to classify pores as micro pores, transitional pores and macro pores.

On the basis of Dubinin's studies, a big number of micro pores of different activated carbons have diameters falling in the range of 4-8 $\times 10-10 \mathrm{~m}$. The size of these pores corresponds to the size of the adsorbing molecules. Transitional pores are bigger than micro pores and have radii from $15-16$ to $1000-2000 \times 10-10 \mathrm{~m}$. Macro pores have diameters above $1000-2000 \times 10-10 \mathrm{~m}$ and are the biggest activated carbon pores.

For better chemisorption, impregnation of activated carbon is performed. Activated carbon is suitable for impregnation because it has a very favorable chemical structure of the surface as well as very developed transitional pores and macro pores which are used as a base for impregnation. The impregnant is deposited in both transitional pores and macro pores of activated carbon. It causes a change of the activated carbon adsorption properties, i.e. it increases the chemisorption capacity for phosgene which is adsorbed by chemisorption and not by physical sorption.

The objective of the study was to increase both sorption capacity and service life of the filter for protection from phosgene toxic effects with a new impregnant, sodium. The objective also included research on the effects of adsorbed water on the adsorption capacity and service life of activated carbon based filters. There were determined the optimal amounts of the impregnant and adsorbed water which increase the sorption capacity and service life of the filters.

\section{EXPERIMENTAL STUDIES}

For the impregnation, there was used activated carbon of the following characteristics:
a) Mass per $\mathrm{dm}^{3}=423 \mathrm{~g}$
b) Ash $=2.43 \%$
c) Volatile matter $=3.71 \%$

The granulometric composition of the activated carbon used in the impregnation was as follows:
a) $>2.00 \mathrm{~mm}$
- $0.9 \%$
b) $>1.6 \mathrm{~mm}$
- $14.3 \%$
c) $>1.25 \mathrm{~mm}$
- $46.9 \%$ 

d) $>1.0 \mathrm{~mm}$
- $18.8 \%$
e) $>0.5 \mathrm{~mm} \quad-17.7 \%$
f) $>2.00 \mathrm{~mm} \quad-0.9 \%$
g) $<0.5 \mathrm{~mm} \quad-1.4 \%$

The impregnation of activated carbon was performed in a vessel rotating around a horizontal axis. The contents of the vessel for impregnation were well homogenized by 60 -minute vessel rotation. Then the carbon was dried to full exemption from moisture.

Characteristics of the carbon obtained by the impregnation are presented in Table (1).

Table 1. Characteristics of the impregnated activated carbon

\begin{tabular}{|c|c|c|c|c|}
\hline $\begin{array}{c}\text { Amount of } \\
\mathrm{Na}(\mathrm{mol})\end{array}$ & $\begin{array}{c}\mathrm{AC} \\
\mathrm{dm}^{3}\end{array}$ & $\begin{array}{c}\text { Masa } \\
\mathrm{AC}(\mathrm{g})\end{array}$ & $\begin{array}{c}\mathrm{Na}(\%) \\
\text { na AC }\end{array}$ & $\mathrm{Na}(\mathrm{g})$ \\
\hline 1 & 1 & 423 & 5,13 & 22,99 \\
\hline 1,1 & 1 & 423 & 5,64 & 25,289 \\
\hline 1,11 & 1 & 423 & 5,689 & 25,518 \\
\hline 1,12 & 1 & 423 & 5,738 & 25,749 \\
\hline 1,13 & 1 & 423 & 5,786 & 25,979 \\
\hline 1,14 & 1 & 423 & 5,834 & 26,209 \\
\hline 1,15 & 1 & 423 & 5,882 & 26,438 \\
\hline 1,16 & 1 & 423 & 5,930 & 26,668 \\
\hline 1,17 & 1 & 423 & 5,978 & 26,898 \\
\hline 1,18 & 1 & 423 & 6,027 & 27,128 \\
\hline 1,19 & 1 & 423 & 6,075 & 27,358 \\
\hline 1,2 & 1 & 423 & 6,12 & 27,588 \\
\hline 1,3 & 1 & 423 & 6,60 & 29,887 \\
\hline
\end{tabular}

The test filters of $105 \mathrm{~mm}$ in diameter and $27 \mathrm{~mm}$ in height were filled with impregnated activated carbon. The impregnated activated carbon contained $\max 7 \%$ moisture.

A dynamic-sorption apparatus was used for the experiment (Figure 1).

From a steel bottle containing phosgene, phosgene is released through the rotameter for phosgene at a flow rate of $25 \mathrm{~cm}^{3} / \mathrm{s}$ into the gas mixer where it is mixed with the air flowing at $475 \mathrm{~cm}^{3} / \mathrm{s}$. In that way $0.5 \mathrm{dm}^{3}$ gas mixture flow containing $0.5 \%$ by vol. phosgene is obtained. The tube through which the air-phosgene mixture passes from the gas mixer splits into two arms. The respiratory filter is connected to one arm while the test filter to the other arm. Relative humidity of the air is manipulated by passing the air through the vessel with water and vessel with concentrated sulfuric acid. As a means of phosgene identification, a standard filter paper strip with diphenylamine and paradimethylaminobenzaldehyde is used.

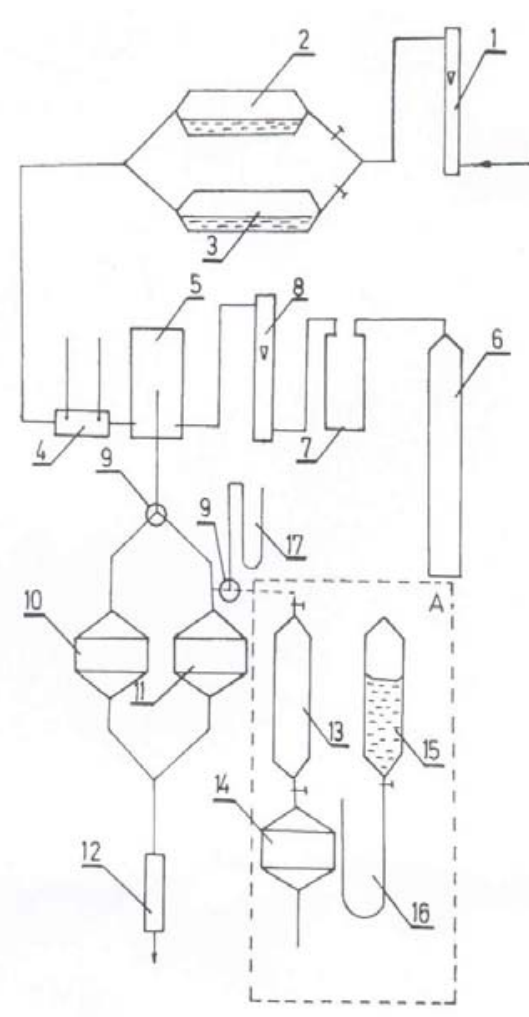

Fig. 1. Apparatus for determination of filter efficiency (The apparatus consists of the following parts: 1 . Rotameter for air, 2. Vessel with concentrated sulfuric acid, 3. Vessel with water, 4. Psychrometer, 5. Mixer, 6. Bottle with phosgene, 7. Supply, 8. Rotameter for phosgene, 9. Three-armed tap, 10. Respiratory filter, 11. Test filter, 12. Indicator, 13. Gas pipette, 14. Respiratory filter, 15. Vessel with KI acetone solution, 16. Rubber hose, 17. Mercury manometer

\section{STUDY RESULTS AND DISCUSSION}

Results of the study are shown in Graphs 1 to 4 .

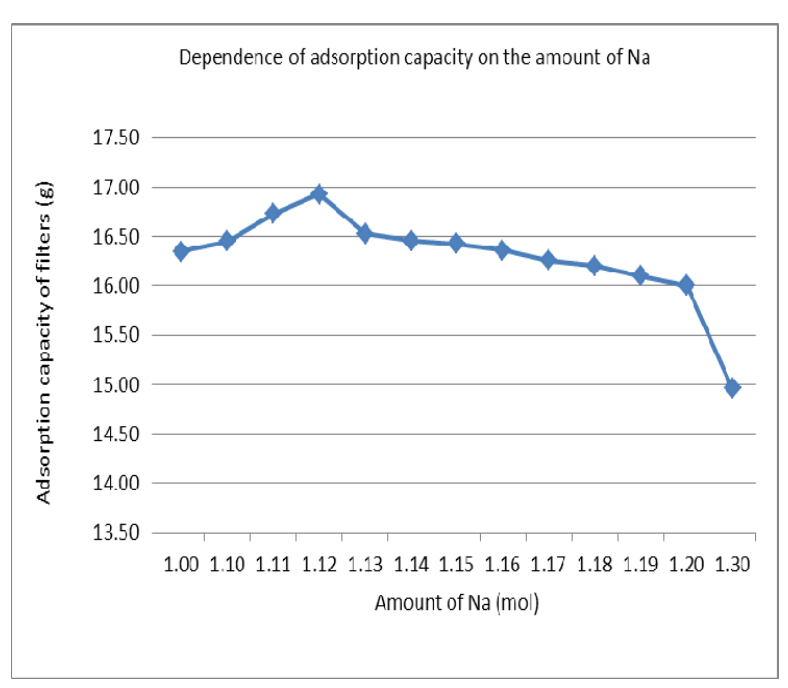

Graph 1. Dependence of adsorption capacity on the amount of $\mathrm{Na}$ 


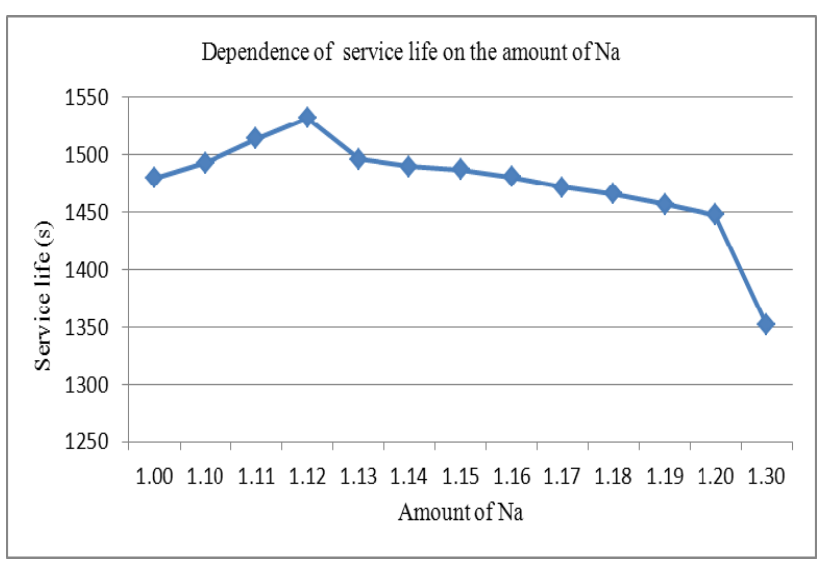

Graph 2. Dependence of service life on the amount of $\mathrm{Na}$

The optimal amount of sodium on the activated carbon which provided the longest service life and the highest adsorption capacity was $1.12 \mathrm{~mol} / \mathrm{dm}^{3}$. This amount of the impregnant provides filters with the service life of $1532 \mathrm{~s}$ and adsorption capacity of $16.93 \mathrm{~g}$. Further increase of impregnation on the activated carbon caused a decrease of both service life and adsorption capacity of the filters. Thus the impregnant of $1.3 \mathrm{~mol}$ provided the filters with the service life of $1352 \mathrm{~s}$ and adsorption capacity of $14.96 \mathrm{~g}$.

The optimal amount of the impregnant filled proportionally the transitional and macro pores of the activated carbon and provided its optimal service life and adsorption capacity.

A greater amount of the impregnant on the activated carbon slows down or prevents phosgene diffusion into the interior of the activated carbon granules where there is also a chemisorbent which remains unused.

In the second phase of the experiment, the effect of the adsorbed water on the activated carbon on the adsorption capacity and service life was investigated. The activated carbon in the filters had $10-35 \%$ adsorbed water. The filters were tested on the apparatus described in the study (Figure 1). Relative humidity of the air during the experiment was $50 \%$.

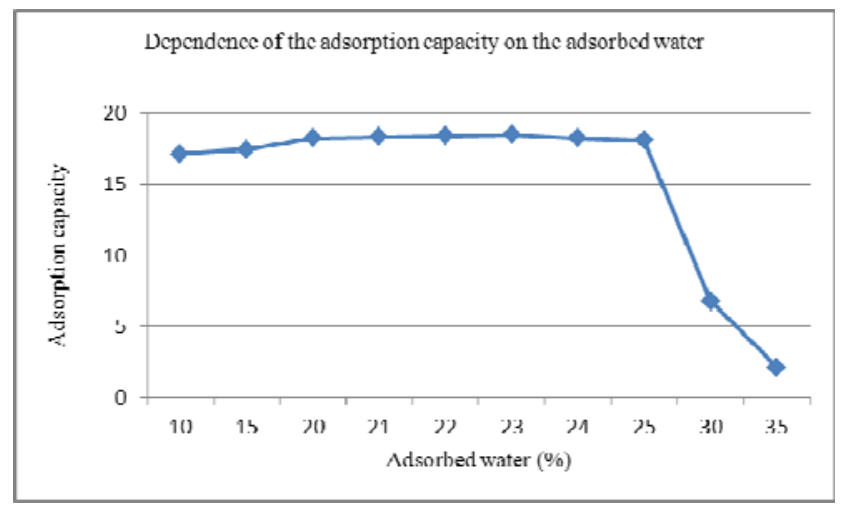

Graph 3. Dependence of the adsorption capacity on the amount of adsorbed water

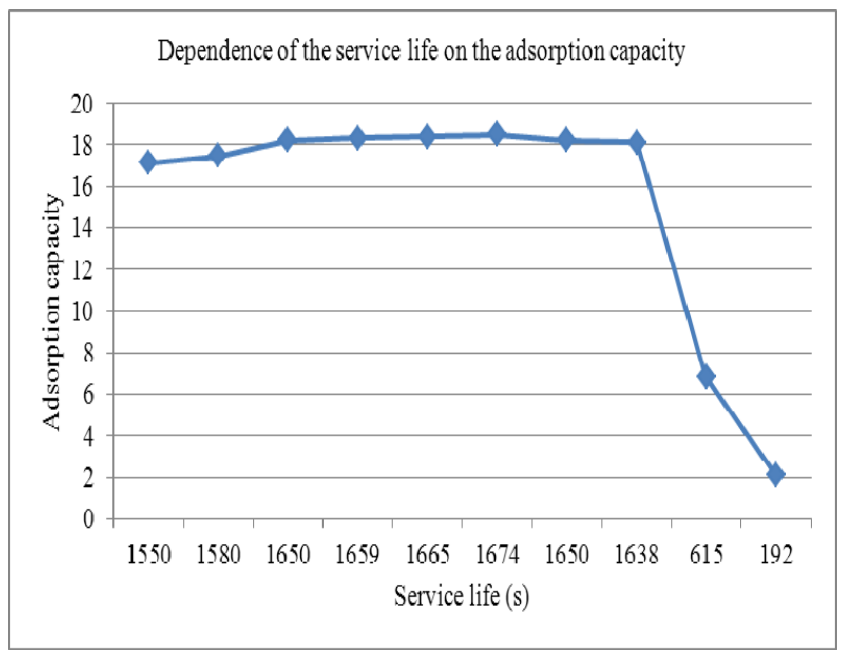

Graph 4. Dependence of the service life on the adsorption capacity

Adsorbed water in the activated carbon filter has a certain effect on the service life and adsorption capacity of the filter. A certain amount of the adsorbed water on the activated carbon has a positive effect on phosgene hydrolysis.

$\mathrm{HCl}$ acid remains on the activated carbon while $\mathrm{CO} 2$ gas being nontoxic releases with the air flow.

However, too big an amount of the adsorbed water has a negative effect because the water occupies a big part of the adsorptive space, i.e. it prevents phosgene molecules from the access to the transitional or macro pores and that affects the adsorption capacity and service life. The optimal amount of the adsorbed water on the activated carbon of the filter is $23 \%$. It provides the filter with the adsorption capacity for phosgene of $18.49 \mathrm{~g}$ and the service life of $1674 \mathrm{~s}$.

\section{CONCLUSION:}

Phosgene is a gas which is widely used in industry and has an extremely toxic effect. In contact with the respiratory organs it causes pulmonary edema and suffocation. Pulmonary edema is caused by hydrochloric acid which is formed in the lung tissue as a result of phosgene hydrolysis. For the protection from phosgene, activated carbon-based filters are used. In the study, impregnation of activated carbon with sodium chemisorbent was performed. The amount of the impregnant used was 1-1.3 mol.

The amount of sodium on the activated carbon with which the optimal service life and optimal adsorption capacity were achieved was $1.12 \mathrm{~mol} / \mathrm{dm}^{3}$. Adsorbed water on the activated carbon also has an effect on phosgene adsorption because it influences phosgene hydrolysis. The products of the hydrolysis are $\mathrm{HCl}$ and $\mathrm{CO} 2$. The acid 
remains on the carbon, and the gas releases with the air flow. The optimal amount of adsorbed water on the activated carbon is $23 \%$.

\section{REFERENCES:}

[1] C.T. Chiou, P.J. Reucroft, Adsorption of phosgene and chloroform by activated and impregnated carbons, Carbon, Volume 15, Issue 2, 1977, Pages 49-53

[2] C. Richard Hall, Richard J. Holmes, The preparation and properties of some activated carbons modified by treatment with phosgene or chlorine, Carbon Volume 30, Issue 2, 1992, Pages 173-176

[3] Frédéric Griolet, Containment of phosgene accidental release-Kinetics of phosgene absorption in sodium hydroxide solution, Chemical Engineering Science, Volume 51, Issue 12, June 1996, Pages 3213-3221

[4] Dorien Wijte, Et al, Toxic effects following phosgene exposure of human epithelial lung cells in vitro using a CULTEX ${ }^{\circledR}$ system, Toxicology in Vitro Volume 25, Issue 8, December 2011, Pages 2080-2087

[5] Jeffrey S. Gift, Robert McGaughy, Dharm V. Singh, Health assessment of phosgene: Approaches for derivation of reference concentration, Regulatory Toxicology and Pharmacology, Volume 51, Issue 1, June 2008, Pages 98107

[6] Cheryl B. Bast, Dana F. Glass, CHAPTER 23 Phosgene, Handbook of Toxicology of Chemical Warfare Agents, 2009, Pages 321-330
[7] Jean-Pierre Senet, Phosgene chemistry and environment, recent advances clear the way to clean processes: a review, Comptes Rendus de l'Académie des Sciences - Series IIC - Chemistry Volume 3, Issue 6, November 2000, Pages 505-516

[8] K.-D. Henning, S. Schäfer, Impregnated activated carbon for environmental protection, Gas Separation \& Purification, Volume 7, Issue 4, 1993, Pages 235-240

[9] Y.-H. Kang, Et al, Using phosphoric acid-impregnated activated carbon to improve the efficiency of chemical filters for the removal of airborne molecular contaminants (AMCs) in the make-up air unit (MAU) of a cleanroom, Building and Environment, Volume 45, Issue 4, April 2010, Pages 929-935

[10] Ki-Joong Kim, Et al, Adsorption-desorption characteristics of VOCs over impregnated activated carbons, Catalysis Today, Volume 111, Issues 3-4, 15 February 2006, Pages 223-228

[11] Abbas Afkhami, Effect of treatment of carbon cloth with sodium hydroxide solution on its adsorption capacity for the adsorption of some cations, Colloids and Surfaces A: Physicochemical and Engineering Aspects, Volume 304, Issues 1-3, 1 September 2007, Pages 36-40 